\title{
EMBnet.jourinal 19.1
}

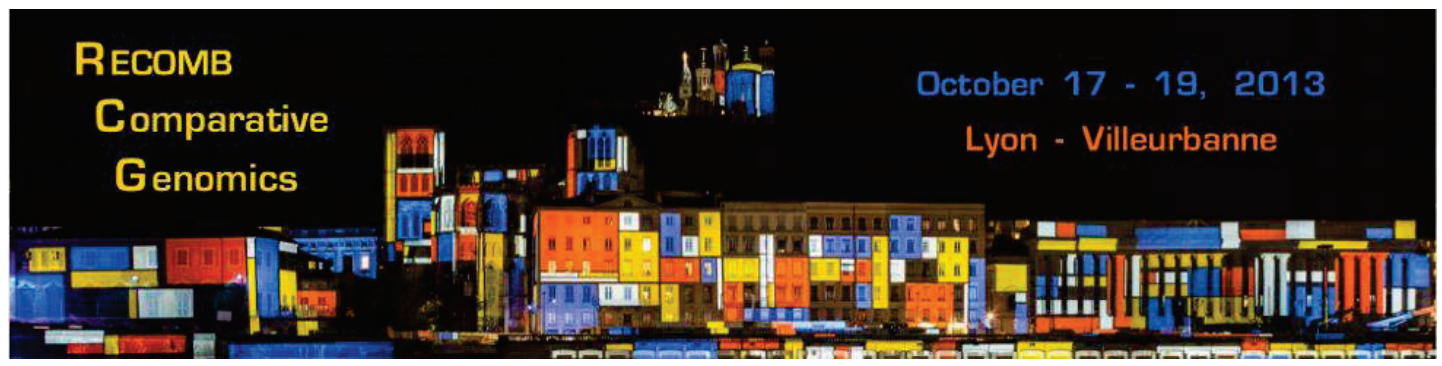

$11^{\text {th }}$ Annual RECOMB Satellite Workshop on Comparative Genomics

The RECOMB Satellite Workshop on Comparative Genomics aims to provide the premier forum for new computational developments applied to all aspects of comparative genomics, including genome structure and organization, genome function, evolution.

\section{http://rcg2013.sciencesconf.org/}

Keynotes speakers:

Tal Dagan, Kiel

France Denoeud, Paris

Laurent Duret, Lyon

Nicolas Galtier, Montpellier

Ludovic Orlando, Copenhagen

Kay Pruefer, Leipzig

Early registration deadline: September $6^{\text {th }}$

Steering committee:

David Sankoff, Aoife Mclysaght, Jens Lagergren

Program committee chairs:

Macha Nikolski, Yves van de Peer

Organizing committee chairs:

Frédéric Brunet, Eric Tannier
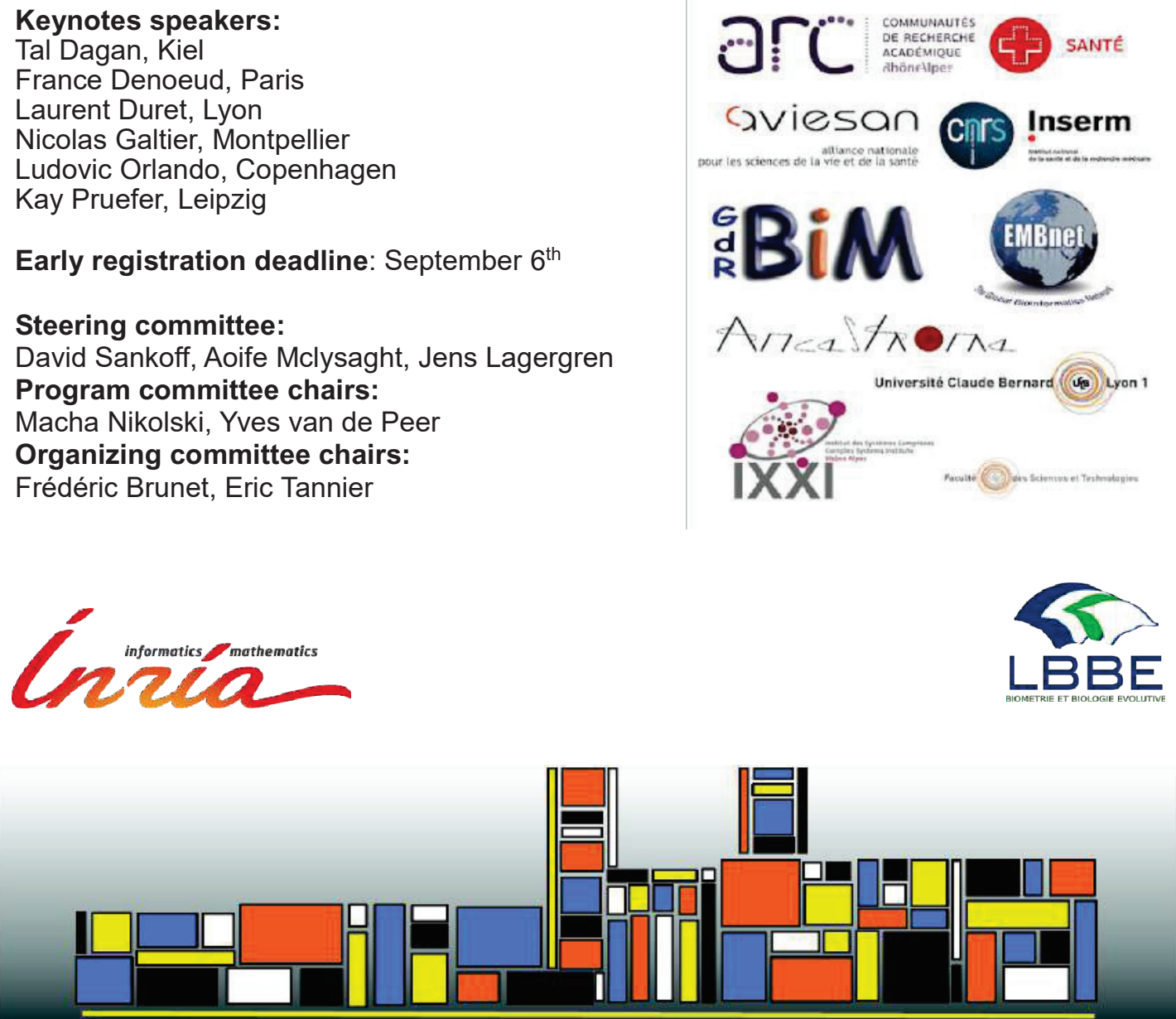

$11^{\text {th }}$ Recomb satellite meeting on Comparative Genomics

Lyon - Villeurbanne (France)

Thu. 17 to Sat. 19 October, 2013 